\title{
On the Improvement Performance of a Dual Rotor Segment Type SRM
}

\author{
Yuma Yoshimaru \\ Graduate School of Engineering Nagasaki University \\ 1-14 Bunkyo, Nagasaki 852-8521, Japan
}

\author{
Tsuyoshi Higuchi, Yuichi Yokoi and Takashi Abe \\ Nagasaki University \\ 1-14 Bunkyo, Nagasaki 852-8521, Japan
}

\begin{abstract}
A dual rotor segment type switched reluctance motor (SRM) is proposed for flat configuration. It has toroidal stator coil and has inner rotor as well as outer rotor. The performance characteristics are calculated using finite element method. On a flat type SRM, leakage flux is greatly generated at both side coil. To reduce the leakage flux we propose shield structure. Effectiveness of the shield structure is verified analytically.
\end{abstract}

\section{INTRODUCTION}

A switched reluctance motor (SRM) is expanding its application area because of its adequate mechanical strength, simple structure, maintenance free and low cost. However, it remains for us to improve performance characteristics and reduce acoustic noise and vibration [1] [2].

We previously proposed a novel segment type SRM in which the stator had full pitch windings and the rotor had segment cores embedded in the aluminum rotor block in order to improve the torque performance and reduce the vibration and acoustic noise compared with conventional variable reluctance type (VR) SRM[3] [4]. However, the copper loss of this motor is greater than the VR type SRM because of the long coil end and it was serious on flat type construction.

To solve the problem, we propose the novel segment type SRM which has toroidal coil windings in the stator and dual rotor structure. This paper explains about the dual rotor segment type novel SRM (DrSRM) and analyses the performance characteristics using the finite element method (FEM). On the flat type SRM, leakage flux is greatly generated at both side coil of the stator. To reduce the leakage flux we propose shield structure. Effectiveness of the shield structure is verified analytically.

\section{SEgMENT TYPE SRM}

\section{A. Inner Rotor Segment Type SRM}

Fig. 1 shows construction of the inner rotor segment type SRM. Segment cores are embedded in the aluminum rotor block and the stator has full pitch three phase windings. Fig. 2 shows torque waveform of the SRM simulated by FEM. The maximum torque is twice as that of a same-sized VR SRM. The average torque is increased by about $40 \%$. The radial force is smaller and so the vibration and acoustic noise are smaller than the VR SRM, because four poles among the six poles are always excited. The iron loss is low because the magnetic path is short [4]. Fig. 3 shows the power factor and efficiency of a $2.2 \mathrm{~kW}, 1,800 \mathrm{rpm}$ test machine. It is shown that the efficiency is about $77 \%$ between $400 \mathrm{~W}$ and $1700 \mathrm{~W}$.

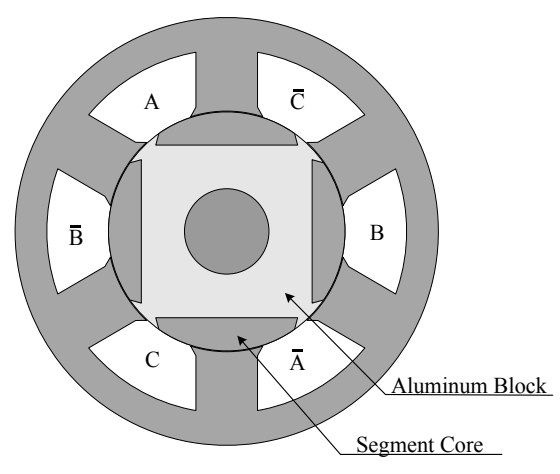

Fig. 1. Construction of segment type SRM.

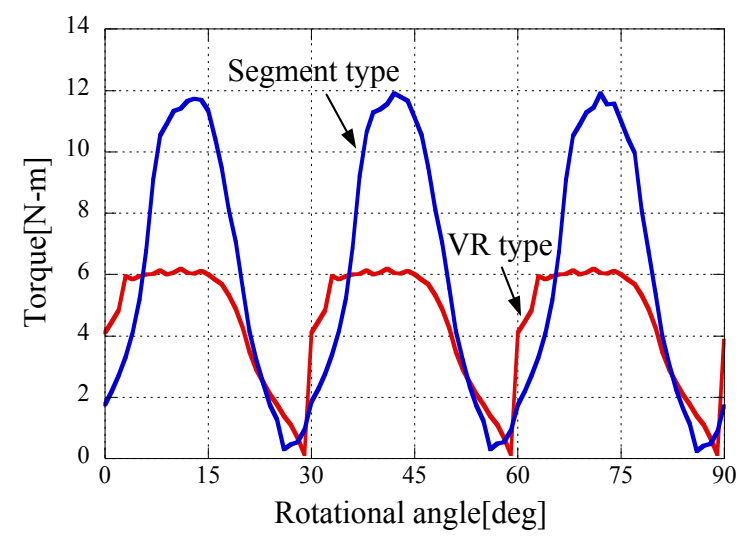

Fig. 2. Torque waveform of segment type SRM. 


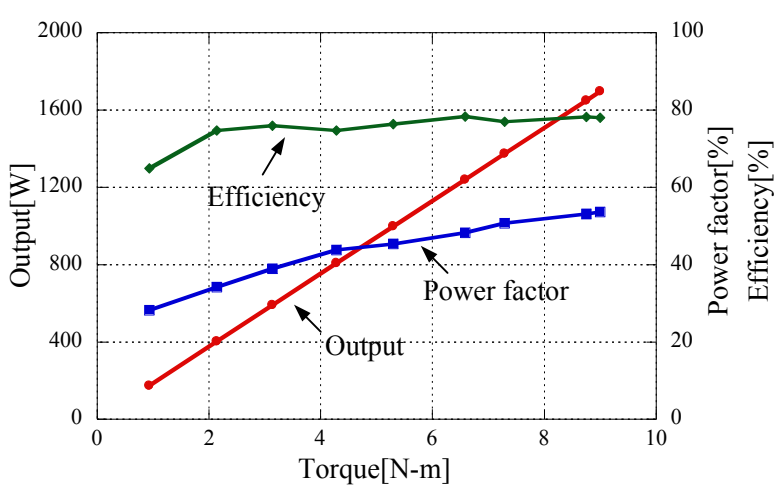

Fig. 3. Characteristics of test machine of segment type SRM.

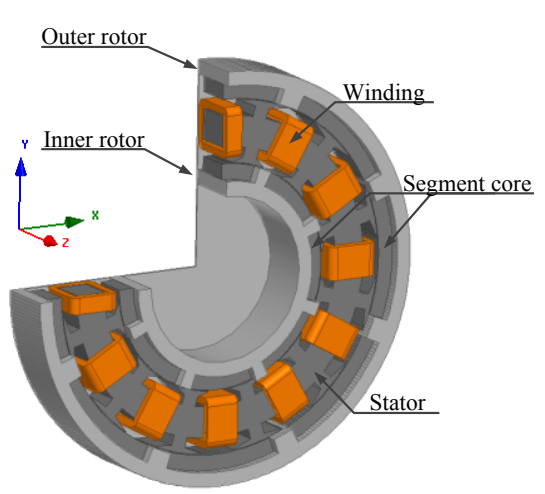

Fig. 4. Construction of DrSRM.

\section{B. Dual Rotor Segment Type SRM}

1) Toroidal coil windings:

Fig. 4 shows a construction of the DrSRM. The stator has toroidal coil windings winded directly to the stator yoke. Fig. 5 compares the average coil length of the full pitch windings and the toroidal coil windings for various motor lengths. If the full pitch windings of the test machine (the motor length is $0.1 \mathrm{~m}$ ) of Fig. 3 are replaced to the toroidal coil windings, the averate coil length will be shorten by about $38 \%$. If the motor length is $0.05 \mathrm{~m}$ (flat configuration), the average coil length will be shorten by $52 \%$. In additon, percentage of copper loss against total loss will be decreaced and the efficiency will be improved.

\section{2) Dual rotor type:}

Each inner and outer part of the stator are facing to an inner rotor and an outer rotor respectively. The inner rotor and outer rotor are casted as one. The magnetic flux distribution is generated both inside and outside of the stator as shown in Fig. 6. It is designed to improve the total torque. It is shown that the dual rotor strucuture makes it possible to increase magnetic efficiency.

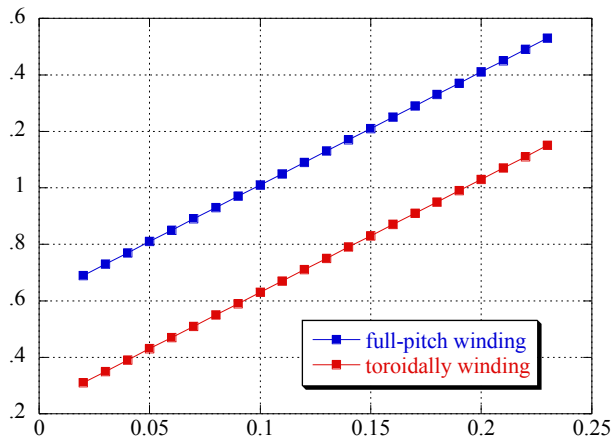

Fig. 5 Average coil length of full pitch and toroidal windings.

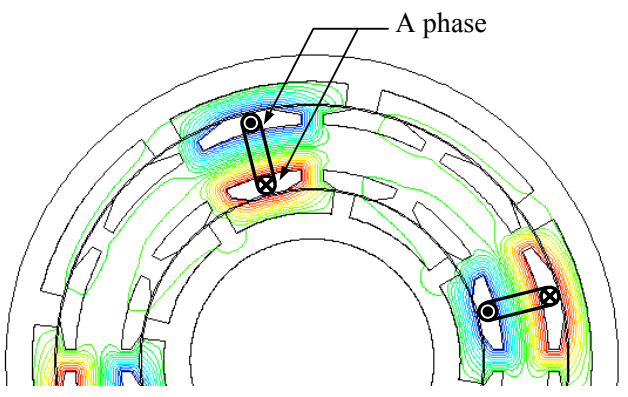

Fig. 6 Magnetic Flux Lines.

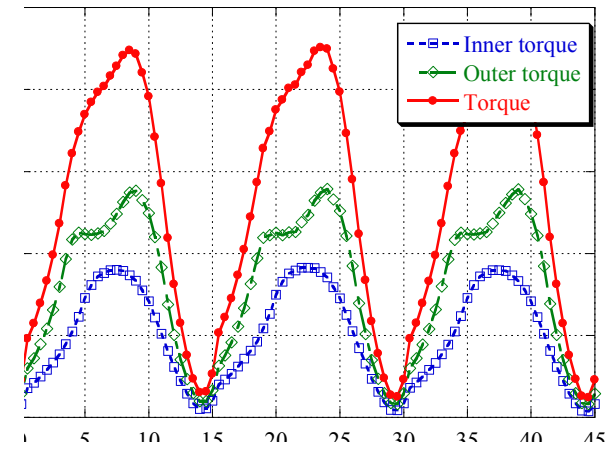

Fig.7 Torque waveform of DrSRM.

Fig. 7 shows the torque waveform of DrSRM simulated by FEM. The torque $T$ is sum of torque generated on inner rotor $T_{i}$ and outer rotor $T_{\mathrm{o}}$. Fig. 8 shows comparison of torque of the DrSRM, inner rotor type SRM and outer rotor type SRM. They are designed same-size and shown in Fig.9. The average torque of DrSRM is increased by about 59\% compared with inner rotor type and about $42 \%$ compared with outer rotor type. 


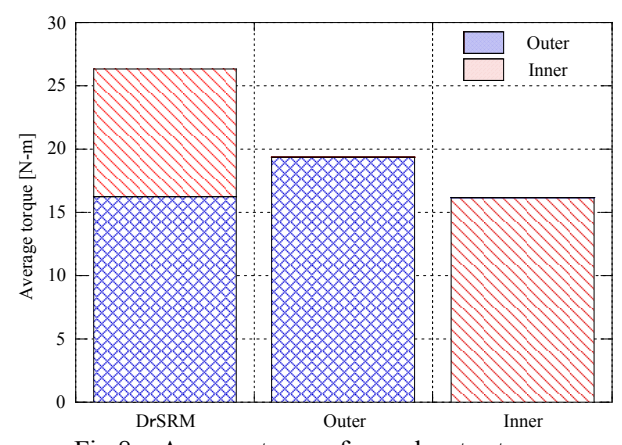

Fig.8 Average torque for each rotor type.

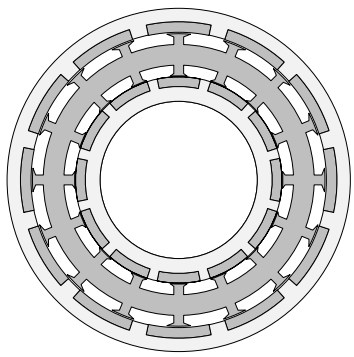

(a)

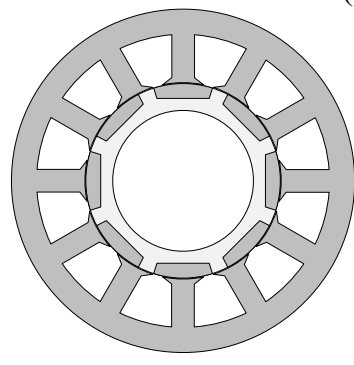

(b)

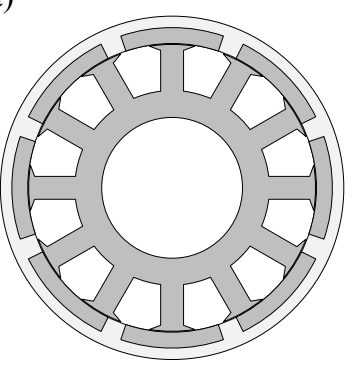

(c)
Fig.9 Analysis model of segment type SRM (a) Dual rotor type, (b) Inner rotor type and (c) Outer rotor type.

\section{The EFFECT Of LEAKAGE FLuX COIL END}

Fig. 10 shows analytical model of DrSRM. The 2-D model is quarter model and the 3-D model is one-eighth model by using the symmetry of the magnetic field as shown in Fig. 10(a) and (b). Fig. 11 shows the analytical results. The difference of the average torque is remarkable as the magneto motive force becomes high (current becomes large). Since the coil end is not taking account in 2-D model, it is thought thet the leakage flux on the coil end is a major course. Fig. shows inductances that are calculated with omitting the $c$ end on the 3-D model. The 3-D model inductance consistent with the results of 2-D. Therefore, the leakage $f$ on the coil end is affecting the torque characteristics.

We try to improve the torque by design optimizati However, it was difficult. So, we propose a shield structure improve the characteristics.

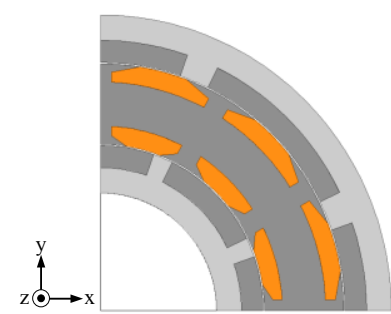

(a)

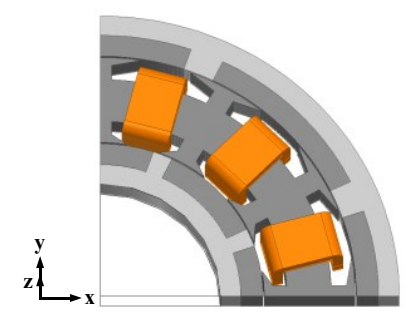

(b)
Fig. 10 Analysis model of DrSRM (a) 2-D, (b) 3-D.

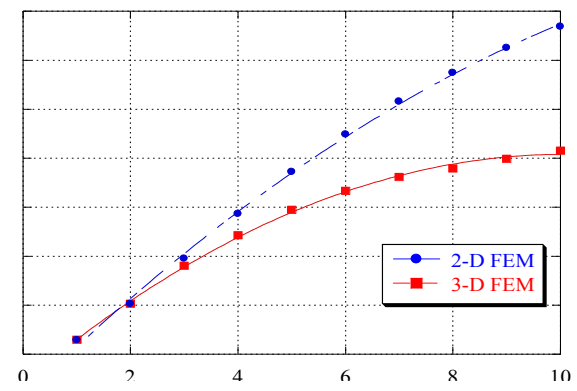

Fig. 11. Average torque-Current for 2-D FEM and 3-D FEM.

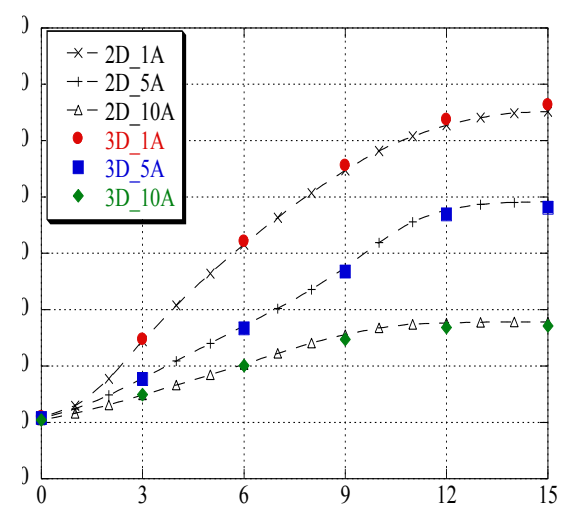

Fig. 12. Inductance waveform.

\section{SHIELD STRUCTURE}

Fig. 13 shows shield structure of the DrSRM. As shown in this figure, a high magnetic permeability material is affixed to both side surfaces of the stator yoke. This material is permendur Fe-Co alloy with a maximum flux density within the soft magnetic material. Fig. 14 shows the characteristics of a permendur and usual electric steel 50H1300.

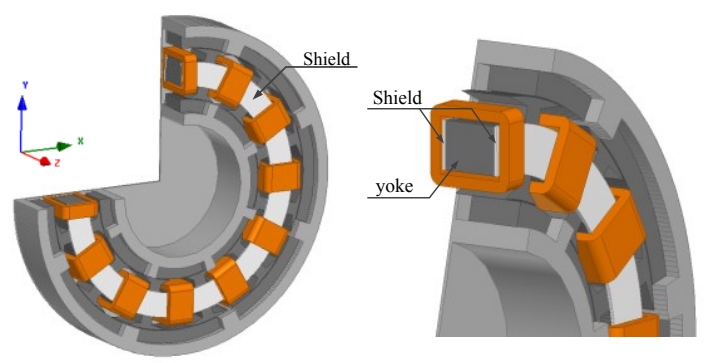

Fig. 13. Construction of Shield structure DrSRM. 


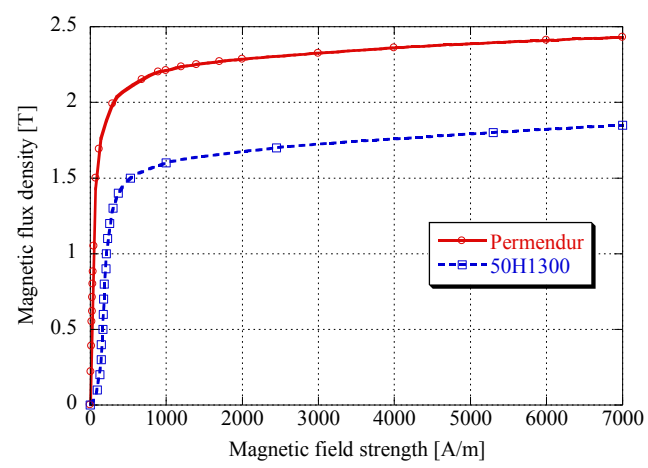

Fig.14 Magnetic characteristics for permendur and 50H1300.

\section{ANALYTICAL RESULT}

In this section, we calculate the torque characteristics of the shield structure model and compare it with the results of Fig. 10 (a) and (b).

The rotational speed is 45rpm and the shield thickness is $0.5 \mathrm{~mm}, 1 \mathrm{~mm}$ and $3 \mathrm{~mm}$.

Analytical results are shown in Table I and Fig. 15. Table I show the torque characteristics of the each model. The 2D model in Table I shows the model of Fig. 10 (a) and the Normal model Fig. 10 (b). In this Table, average torque has been improved with an increase in the shield thickness and the average torque of $3 \mathrm{~mm}$ shield structure is improved $2.6 \mathrm{~N}-\mathrm{m}$ compared with that of normal model. Fig. 15 shows the torque waveforms. It is shown that the torque of the shield structure is approaching to that of $2 \mathrm{D}$ with increasing thickness. Therefore, we consider that shield structure is available for improving the torque by reducing the leakage flux of both side surfaces of the stator yoke.

\section{CONCLUSIONS}

In this paper, we analyzed the dual rotor type SRM and show the torque reduction on flat configuration motor. To improve the torque reduction we proposed the shield structure. We confirmed the torque became nearly 2-D model results with increasing shield thickness.

TABLE I. AVERAGE TORQUE CHARACTERISTICS

\begin{tabular}{|c|c|c|c|}
\hline \multicolumn{2}{|c|}{ Model } & $\begin{array}{c}\text { shield thickness } \\
{[\mathbf{m m}]}\end{array}$ & $\begin{array}{c}\text { average torque } \\
{[\mathbf{N}-\mathbf{m}]}\end{array}$ \\
\hline \multicolumn{2}{|c|}{ 2D } & - & 27.0 \\
\hline \multirow{3}{*}{$3 \mathrm{D}$} & Normal & - & 23.0 \\
\cline { 2 - 4 } & \multirow{3}{*}{$\begin{array}{c}\text { Shield } \\
\text { structure }\end{array}$} & 0.5 & 23.6 \\
\cline { 3 - 4 } & & 1 & 24.1 \\
\cline { 3 - 4 } & & 3 & 25.6 \\
\hline
\end{tabular}

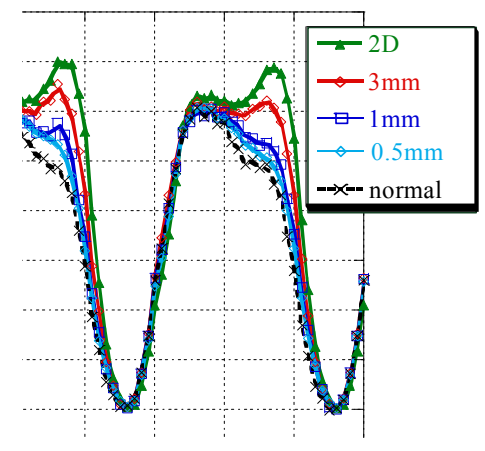

Fig. 15. Torque waveform.

\section{REFERENCES}

[1] T. J. E. Miller, Ed., "Switched Reluctance Motors and their Control", Lebanon, OH: Magna Physics/Oxford University Press, 1993.

[2] T. J. E. Miller, Ed., "Electronic Control of Switched Reluctance Motors", ser. Newnes Power Engineering Series. Oxford, U.K. Newnes, 2001

[3] J. Oyama, T. Higuchi, T. Abe, and N. Kifuji : "Novel Switched Reluctance Motor with Segment Core Embedded in Aluminum Rotor Block", IEEJ Trans. IA, Vol.126, No4, pp.385-390, 2005.

[4] J. Oyama, T. Higuchi, T. Abe, and K. Tanaka: "The Fundamental Characteristics of Novel Switched Reluctance Motor with Segment Core Embedded in Aluminum Rotor Block", Journal of Electrical Engineering \& Technology, Vol. 1, No.1, pp. 58-62, 2006. 